Info Artikel Diterima Mei 2017

Disetujui Agustus 2017

Dipublikasikan April 2018

\title{
POLA DISTRIBUSI DAN MARGIN PEMASARAN GABAH DI KABUPATEN KARAWANG
}

\author{
Nurul Aenunnisa, Djoko Sumarjono, Mukson \\ Program Studi S1Agribisnis, Departemen Pertanian, \\ Fakultas Peternakan dan Pertanian Universitas Diponegoro Semarang \\ E-mail: nurulaenunnisa@ student.undip.ac.id
}

\begin{abstract}
The purpose of this research is to analyze the difference of government floor price of grain with the average costs of paddy, analyzing the distribution pattern of grain amd amalyze marketing margins of grain in Karawang Region. The benefit from this research is to design and efficient the grain distribution in Karawang Region and this study can be used as reference for practitioners and stakeholder in taking policy on grain price. Methods used in this study is survey. The location chosen by purposive. The amount of respondent were 82 respondents using the snowball method. The analysis using descriptive and statistics One sample t-test, the calculation of the avarage cost of paddy, the percentage of patterns and the calculation of the margin marketing. The results showed that there are differences of grain price of avarage cost by IDR. 3.531 and the price of grain non government by an average of IDR. 4.347 with the floor price of the government (HPP) commodity the grain by IDR. 3.700 in significantly. There are two patterns of marketing grain which is a long pattern there are farmers broker - ricemill with the percentage of $67 \%$, and the short pattern there are farmers - ricemill with the percentage of $33 \%$. The margin value of long pattern by IDR. 250 per kilogram, while the short pattern IDR. 0 per kilogram. There are differences, the long pattern with the short pattern in significant.
\end{abstract}

Keywords: Farming, operational cost paddy, pattern, margin.

\section{PENDAHULUAN}

Pembangunan di Indonesia terutama dalam bidang pertanian telah mengarah pada upaya peningkatan produksi pangan dan pendapatan petani. Hal tersebut ditunjukkan dengan adanya dukungan dari pemerintah melalui kegiatan ekonomi petani untuk mencapai produksi gabah yang melimpah. Produksi gabah yang melimpah pada saat panen raya menyebabkan timbulnya fluktuasi harga gabah di tingkat petani. Salah satu faktor yang mempengaruhi fluktuasi harga di tingkat petani adalah adanya selisih harga pasar pada tingkat petani dengan penggiling dalam bentuk Gabah Kering Panen (GKP). Harga GKP ditingkat petani dan penggiling pada Bulan Agustus 2016 sebesar Rp. 4.479,51 dan Rp. 4.563,69 per kg (Badan Pusat Statistik, 2016). Selisih harga GKP terjadi akibat adanya rantai pemasaran melalui penyalur yang menekan harga petani dan memberikan penawaran tinggi terhadap penggiling. Selisih harga tersebut akan mempengaruhi harga beras yang akan ditawarkan oleh penggiling.

Permasalahan di atas menjadi dasar pemerintah untuk melindungi kesejahteraan petani dari tekanan harga GKP rendah yang ditetapkan penyalur dengan menetapkan Harga Pembelian Pemerintah (HPP) berdasarkan INPRES 
5/2015 tanggal 17 Maret 2015 agar harga GKP tidak jatuh hingga menimbulkan kerugian di tingkat petani dengan melaksanakan kebijakan pengadaan gabah/beras melalui pembelian gabah/beras dalam negeri dengan ketentuan Harga Pembelian Pemerintah (Badan Ketahanan Pangan Pertanian, 2015). Harga pembelian pemerintah yang telah ditetapkan pada tahun 2015 belum sesuai dan tidak tepat digunakan pada tahun 2017 disebabkan harga pembelian pemerintah tahun 2015 tidak menguntungkan bagi petani. Kerugian tersebut terjadi karena biaya operasional budidaya tanaman padi di Karawang lebih besar dari pada harga pembelian pemerintah (HPP) komoditas Gabah. Harga pembelian gabah non pemerintah juga lebih besar daripada harga pembelian pemerintah (HPP). Harga jual gabah pada tahun 2015 pada musim kemarau melebihi harga pembelian pemerintah GKG sebesar Rp.3.750/kg. Harga GKP saat itu dibeli oleh penyalur rata-rata di atas Rp.4.200/Kg (Kadarrisman, 2016). Permasalahan di atas diperlukan kajian tentang perbedaan harga gabah yang ditetapkan oleh permerintah dengan biaya budidaya tanaman padi, pola distribusi, dan perhitungan margin pemasaran sehingga dapat lebih efisien. Tujuan penelitian ini adalah: a). Mengetahui dan menganalisis perbedaan harga gabah pembelian pemerintah dan non pemerintah dengan beban biaya operasional budidaya padi, b). Mengetahui dan menganalisis pola distribusi gabah, dan c). Mengetahui dan menganalisis margin pemasaran gabah dalam rantai distribusi gabah di Kabupeten Karawang.

\section{METODE PENELITIAN}

Gabah merupakan bahan pokok pangan apabila telah diolah dan dipisahkan antara sekam, dedak dan daging gabah hingga merubah fisik menjadi beras yang kemudian dikonsumsi oleh seluruh insan dunia, terkhusus masyarakat Indonesia yang konsumsi pangan pokok utama adalah beras. Mengingat Peraturan Pemerintah Republik Indonesia Nomor 17 Tahun 2015, tentang Ketahanan Pangan dan Gizi dalam Bab, Pasal 1, Ayat 12 dan 15 yaitu "Distribusi pangan adalah suatu kegiatan atau serangkaian kegiatan untuk menyalurkan pasokan pangan secara merata setiap guna memenuhi kebutuhan pangan masyarakat". Serta "Pangan pokok tertentu adalah pangan pokok yang diproduksi dan dikonsumsi oleh sebagian besar masyarakat Indonesia yang apabila ketersediaan dan harganya terganggu dapat memengaruhi stabilitas ekonomi dan menimbulkannya gejolak sosial di masyarakat". Mengulas peraturan yang ditetapkan di atas permasalahan fluktuatifnya harga beras dibidang pemasaran akan berpengaruh terhadap konsumsi masyarakat. Salah satu faktor tersebut adalah ketimpangan harga pasar pada tingkat petani dan penggiling terhadap harga gabah yaitu Gabah Kering Panen (GKP).

Ketimpangan harga menunjukkan bahwa adanya selisih harga yang diterima petani dengan yang dibayarkan oleh penggiling. Selisih harga terjadi diakibatkan oleh adanya rantai pemasaran atau pola distribusi antara petani dengan penggiling.

Pemerintah telah berupaya dalam stabilisasi harga gabah di pasar agar petani dapat terlindungi kesejahteraannya dari ancaman tekanan harga penyalur dengan menetapkan Harga Pembelian Pemerintah (HPP) atau harga dasar (Floor Price). Faktanya, harga dasar yang telah ditetapkan oleh pemerintah tidak menguntungkan bagi petani dalam menstabilkan harga pasar, terkait pada total 
penerimaan yang diperoleh berdasarkan harga dasar belum sepenuhnya menutupi beban biaya operasional budidaya yang dikeluarkan oleh petani Akibatnya penerimaan harga jual gabah per kilogram lebih besar dari harga dasar yang telah ditetapkan pemerintah dalam satuan kilogram. Dari permasalahan yang diuraikan di atas maka diperlukannya survey rantai penyaluran gabah secara efisien, meninjau margin pemasaran gabah dan bagaimana perbedaan harga dasar yang ditetapkan pemerintah dengan beban biaya operasional budidaya tanaman padi yang menjadi faktor keuntungan dan menguntungkan bagi petani.

\section{Metode Penelitian}

Metode penelitian dilakukan dengan metode survei. Lokasi penelitian ditentukan secara purvosive sampling diambil dengan sampel 3 kecamatan yaitu yaitu Kecamatan Rawamerta, Kecamatan Karawang Barat dan Kecamatan Majalaya. Waktu penelitian dilaksanakan pada tanggal 13 Januari - 23 Februari 2017. Metode penentuan jumlah sampel bagi petani dilakukan secara Snowball sampling dan penentuan responden yang dipilih dilakukan secara purposive. Jumlah sampel yang diperoleh yaitu 82 responden dengan formula 69,51\% responden petani, $17,07 \%$ responden tengkulak dan $13,42 \%$ responden penggiling. Lokasi dan jumlah responden dapat di lihat di Tabel 1.

Sumber dan jenis data yang digunakan adalah data primer diperoleh dengan cara langsung melalui wawancara yang berpedoman pada kuisioner kepada petani, tengkulak penggiling dan data sekunder diperoleh dari berbagai instansi yang relevan seperti BPS, Bapedda, dan sumber lainnya.

Tabel 1. Lokasi Penelitian dan Jumlah Sampel

\begin{tabular}{lcrrrrrr}
\hline \multirow{2}{*}{ No } & Lokasi & \multicolumn{6}{c}{ Sampel } \\
\cline { 3 - 8 } & Penelitian & \multicolumn{2}{c}{ Petani } & \multicolumn{2}{c}{ Tengkulak } & \multicolumn{2}{c}{ Penggiling } \\
\cline { 3 - 8 } & & Jumlah Persentase Jumlah & Persentase & Jumlah Persentase \\
\hline \multirow{2}{*}{1} & Rawamerta & (Orang) & $--(\%)--$ & (Orang) & $--(\%)--$ & (Orang) & $--(\%)--$ \\
2 & Karawang Barat & 22 & 31,58 & 3 & 21,43 & 4 & 36,36 \\
3 & Majalaya & 17 & 29,82 & 7 & 50,00 & 1 & 9,09 \\
\hline & Total & 57 & 100,00 & 14 & 100,00 & 11 & 100,00 \\
\hline
\end{tabular}

Sumber: Data Primer Terolah, 2017

\section{Analisis Data}

Analisis yang digunakan sebagai berikut:

1. Analisis biaya budidaya tanaman padi dan uji perbedaan harga pembelian pemerintah GKP dengan biaya operasional budidaya tanaman padi dengan One Sample T-Test menggunakan SPSS.

Biaya operasional budidaya merupakan Total Cost (TC) yang diperoleh dari jumlah Fix Cost (FC) dan Variabel Cost (VC). Persamaannya sebagai berikut:

$$
\mathrm{TC}=\mathrm{FC}+\mathrm{VC}
$$

Dimana:

TC : Total biaya $(\mathrm{Rp})$

FC : Biaya tetap (Rp)

$\mathrm{VC} \quad$ : Biaya variabel(Rp) 
Biaya operasional budidaya dinyatakan dalam satuan rupiah per kilogram sehingga total jumlah biaya produksi di bagi dengan hasil produksi. Persamaannya sebagai berikut:

$\begin{array}{ll}\text { Dimana } & \text { HPP } \quad \text { TC / S } \\ \text { HPP } & : \text { Harga Pokok Produksi }(\mathrm{Rp} / \mathrm{Kg}) \\ \text { TC } & \text { : Total Biaya (Rp) } \\ \mathrm{S} & \text { : Hasil Produksi (Kg) }\end{array}$

Analisis one sample t-test digunakan untuk menguji signifikansi perbedaan suatu nilai rata-rata dengan nilai tertentu (test value = harga pembelian pemerintah. Alat yang digunakan dalam uji beda one sample t-test yaitu dengan SPSS. Merumuskan hipotesis statistik

$\mathrm{H} 0: \mu 1=$ Rp. 3.700

(Tidak terdapat perbedaan harga gabah dari beban biaya budidaya tanaman padi dengan harga pembelian pemerintah komoditas gabah terhadap keuntungan petani).

$\mathrm{H} 1: \mu 1 \neq$ Rp. 3.700

(Terdapat perbedaan harga gabah dari beban biaya budidaya tanaman padi dengan dengan harga pembelian pemerintah komoditas gabah terhadap keuntungan petani).

$\mathrm{H} 0: \mu 2=$ Rp. 3.700

(Tidak terdapat perbedaan harga non pemerintah dengan harga pemerintah terhadap keuntungan petani).

H1 : $\mu 2 \neq$ Rp. 3.700

(Terdapat perbedaan harga non pemerintah dengan harga pemerintah terhadap keuntungan petani), dimana:

$\mu 1 \quad=$ Biaya operasional budidaya padi.

$\mu 2=$ Harga pembelian non pemerintah atau harga pasar

Rp. $3.700=$ Harga pembelian pemerintah komoditas gabah.

H0 ditolak jika signifikasi kurang dari 5\% $(0,050)$.

2. Hipotesis Pola Distribusi Pemasaran Gabah di Kabupaten Karawang diuji Dengan Analisis Deskriptif Persen

Deskriptif persentase ini diolah dengan cara frekuensi dibagi dengan jumlah responden dikali 100 persen, seperti dikemukakan Fauzy (2011) adalah sebagai berikut:

Dimana:

P : Persentase

$\mathrm{F} \quad$ : Frekuensi

$\mathrm{N} \quad$ : Jumlah responden

3. Hipotesis Margin Pemasaran Gabah di Kabupaten Karawang di Uji dengan Analisis Margin Pemasaran

Menurut Fanini (2012), perhitungan margin pemasaran digunakan rumus:

Dimana:

$$
\mathrm{Mm}=\mathrm{Pr}-\mathrm{Pf}^{\prime}
$$

$\mathrm{Mm}=$ Margin pemasaran di tingkat petani . 
$\operatorname{Pr} \quad=$ Harga di tingkat kelembagaan pemasaran tujuan pemasaran dari petani.

Pf $\quad=$ harga di tingkat petani

Berdasarkan pola yang di ambil dari setiap saluran maka menentukan nilai dari margin. Adanya margin menunjukkan adanya selisih harga dari petani hingga penggilingan.

\section{HASIL DAN PEMBAHASAN}

\section{Karakteristik Responden}

Petani yang menjadi responden di dominasi dengan jenis kelamin laki-laki, pendidikan SD, petani berada pada usia produktif, pekerjaan utama sebagai petani, lama bertani lebih dari 3 tahun, luas lahan garapan > 1 Ha, kadar GKP dibawah $25 \%$ sehingga harga GKP berada antara 4000 - 4500. Kebanyakan petani menjual ke tengkulak dan penggiling. Tengkulak dan penggiling yang menjadi responden di dominasi dengan jenis kelamin laki-laki, pendidikan tengkulak berada pada jenjang SD dan penggiling berada pada jenjang SMA, tengkulak dan penggiling berada pada usia produktif, pekerjaan utama sebagai wirausaha, lama usaha berada pada 1 - 30 tahun, Pendistribusian di daerah lokal dan non lokal.

\section{Biaya Budidaya Padi}

Kegiatan dalam budidaya tanaman padi tidak terlepas dari beban biaya. Beban biaya merupakan kumpulan dari biaya-biaya yang harus dikeluarkan oleh para petani. Para petani di Kabupaten Karawang harus mengeluarkan beban biaya meliputi biaya tetap dan biaya variabel yang dipadukan sehingga menjadi total biaya. Dari total biaya tersebut maka akan menghasilkan harga pokok produksi untuk satu kilogram harga gabah. Ekowati et al. (2014) mengungkapkan bahwa biaya usahatani merupakan beban berbentuk uang dalam kurun waktu tertentu meliputi pengeluaran tunai dan non tunai. Menurut Badan Pusat Statistika (2015) bahwa biaya produksi pada budidaya tanaman padi meliputi biaya bibit sebesar $3,20 \%$, pupuk sebesar $10,40 \%$, pestisida sebesar $1,9 \%$, upah pekerja (pengolahan lahan $7,60 \%$, penanaman dan penyulaman $7,50 \%$, pemeliharaan $6,20 \%$, pemupukan 2,30\%, pengendalian OPT 2,30\%, pemanenan-perontokanpengangkutan $10,10 \%$ dan jasa pertanian $12,40 \%$ ) sebesar $35,90 \%$, sewa lahan sebesar 29,90\%, sewa alat atau sarana usaha sebesar 2,60\%, bahan bakar sebesar $0,70 \%$ dan biaya produksi lain-lainnya sebesar 3,20\% .

\section{Biaya Tetap}

Biaya tetap adalah biaya yang harus dikeluarkan para petani dengan jumlah totalnya tidak akan berubah apabila jumlah barang uang akan diproduksi bertambah. Biaya tetap dalam budidaya tanaman padi meliputi biaya lahan (sewa atau pajak) dan biaya penyusutan alat. Biaya tetap dapat dilihat pada Tabel 2.

Berdasarkan Tabel 2 biaya tetap pada budidaya tanaman padi di Kabupaten Karawang meliputi biaya lahan yang terdiri dari pajak dan sewa lahan, dan biaya penyusutan yang terdiri dari alat seperti cangkul, pedang, sprayer dan mesin seperti traktor, power tresher. Berikut yang termasuk kedalam biaya tetap disebabkan bertambah dan berkurangnya kuantitas produksi tidak akan mempengaruhi nilai biaya diatas sehingga biaya-biaya tersebut dikelompokkan kedalam biaya tetap. Ekowati et al. (2014) mengungkapkan bahwa biaya tetap 
merupakan biaya yang besarnya tidak merubah total dengan berubahnya jumlah produk.

Tabel 2. Rata-rata Biaya Tetap Budidaya Tanaman Padi di Kabupaten Karawang

\begin{tabular}{clrr}
\hline No & \multicolumn{1}{c}{ Uraian } & \multicolumn{1}{c}{ Biaya } & \multicolumn{1}{c}{ Persentase } \\
\hline \multirow{2}{*}{1} & Lahan & $---(\mathrm{Rp})---$ & \multicolumn{1}{c}{$-(\%)---$} \\
& a). Pajak & 127.097 & 2,84 \\
& b). Sewa & 2.028 .102 & 45,26 \\
2 & Penyusutan & & \\
& a). Cangkul & 4.016 & 0,09 \\
& b). Pedang & 7.422 & 0,16 \\
& c). Sprayer & 55.334 & 1,23 \\
& d). Traktor & 1.005 .469 & 22,44 \\
& e). Power Tresher & 1.253 .906 & 27,98 \\
\hline Total & & 4.481 .347 & 100,00 \\
\hline
\end{tabular}

Sumber: Data Primer Terolah, 2017.

\section{Biaya Variabel}

Biaya variabel adalah biaya yang dikeluarkan para petani apabila jumlah produksi ditingkatkan atau diturunkan akan merubah nilai jumlahnya sehingga jumlah produksi mempengaruhi beban biaya yang akan diperoleh. Semakin banyak produksi maka semakin besar beban yang akan diperoleh. Sesuai dengan pendapat Ekowati et al.(2014) bahwa biaya variabel merupakan biaya yang totalnya akan berubah dengan berubahnya jumlah produk.

Berdasarkan Tabel 3, biaya variabel pada budidaya tanaman padi meliputi biaya sarana produksi yang terdiri dari benih, pupuk, pestisida dan prasarana yang terdiri dari tenaga kerja dan biaya lain-lain. Beban terbesar dari ke-tiga komponen diatas (benih, pupuk, pestisida) yang memiliki beban terbesar berada di komponen pestisida. Kondisi tersebut terjadi disebabkan wilayah Kabupaten Karawang pada masa tanam Oktober - Maret dihadapi dengan kendala hama yang muncul secara serempak. Petani terus berupaya memberantas hama yang menyerang tanaman padi agar tidak terjadi kegagalan panen sehingga akan merugikan petani. Upaya tersebut tentunya berhubungan dengan tenaga kerja yang dibebankan dalam aktivitas produksi.

Tenaga kerja harian digunakan sesuai dengan kebutuhan pada proses budidaya padi baik dalam segi kondisi kesehatan tanaman, lahan, iklim, dan organisme pengganggu tanaman sehingga jumlah dan periode pelaksanaan dalam setiap musim tanam tenaga kerja harian tidak selalu sama. Tenaga kerja harian dibayarkan sesuai kesepakatan pemilik lahan dengan buruh tani. Tenaga kerja harian di Kabupaten Karawang ada yang menggunakan tenaga kerja luar dan adapula yang menggunakan tenaga kerja dalam keluarga yang diperhitungkan. 
Tabel 3. Rata-rata Biaya Variabel Budidaya Tanaman Padi di Kabupaten Karawang

\begin{tabular}{|c|c|c|c|c|c|}
\hline No & Uraian & Jumlah & $\begin{array}{l}\text { Harga } \\
\text { satuan }\end{array}$ & Biaya & Persentase \\
\hline 1 & Benih & 21 & 7.361 & $\begin{array}{r}---(\mathrm{Rp})--- \\
151.600\end{array}$ & $\begin{array}{r}---(\%)--- \\
0,77\end{array}$ \\
\hline 2 & Pupuk & & & & \\
\hline & a) Urea & 254 & 1.883 & 477.918 & 2,45 \\
\hline & b) SP36 & 303 & 2.164 & 655.314 & 3,36 \\
\hline & c) NPK Ponska & 189 & 2.339 & 441.636 & 2,26 \\
\hline 3 & Pestisida & 9 & 739.309 & 6.991 .011 & 35,81 \\
\hline
\end{tabular}
a). Tenaga Kerja
Harian
JK HOK L P

1). Pengolahan lahan

2). Pembibitan

$\begin{array}{llll}8 & 3 & 1 & 0\end{array}$

100.000

363.273

1,86

$\begin{array}{llll}4 & 2 & 1 & 0\end{array}$

67.807

99.353

0,51

3). Penyemaian

$\begin{array}{llll}4 & 4 & 1 & 0\end{array}$

67.807

381.959

1,96

4). Penyulaman

$\begin{array}{llll}4 & 3 & 1 & 0\end{array}$

$67.807 \quad 289.909$

1,49 dan Penyiangan

$\begin{array}{llll}4 & 2 & 1 & 0\end{array}$

67.807

202.808

1,04

6). Pengairan

$\begin{array}{llll}4 & 13 & 1 & 0\end{array}$

67.807

505.105

2,59

7). Pengendalian OPT

$\begin{array}{llll}4 & 9 & 1 & 0\end{array}$

67.807

840.309

4,3

b) Tenaga Kerja

Borongan
1). Pembajakan
2). Penanaman
3). Panen
1
1.000 .000
1.000 .000
5,12
$1 \quad 1.000 .000$
1.000 .000
5,12
4). Perontokan
3.978 .978
3.978 .978
20,38
5,9
$170.000 \quad 1.019 .890$
5,22

5 Biaya lain-lain
a). Bensin Traktor
33
6.938
228.842
1,17
b). Bensin Rontok
43
6.875
297.953
1,53
c). Plastik Semai
31.000
31.000
0,16
d) Iuran Irigasi
4.347
86.947
0,46
e). Karung
20
f). Benang
3.000
450.206
2,31
14.154
21.659
0,11
g). Jarum
2.765
4.886
0,02
2
19.520 .556
100,00

Total

Sumber: Data Primer Terolah, 2017.

Keterangan:

$\mathrm{JK}=$ Jam Kerja

L = Laki-laki

$\begin{array}{ll}\mathrm{HOK} & =\text { Hari Orang Kerja } \\ \mathrm{P} & =\text { Perempuan }\end{array}$ 


\section{Biaya Operasional}

Biaya Operasional Budidaya Tanaman Padi merupakan keseluruhan beban biaya yang dikeluarkan dalam satu kali produksi. Produksi budidaya tanaman padi dilakukan oleh petani di Kabupaten karawang terdiri dari biaya tetap dan biaya variabel. Ekowati et al. (2014) mengungkapkan bahwa struktur biaya produksi atau operasional terdiri dari biaya variabel dan biaya tetap.

Hasil pengolahan biaya tertinggi dengan skala biaya operasional budidaya tanaman padi berada pada biaya variabel dengan beban biaya sebesar Rp.19.520.556 dengan persentase $81,33 \%$ dari biaya operasional budidaya tanaman padi sebesar Rp.24.001.903., sedangkan biaya tetap dibebankan sebesar Rp.4.481.347 dengan persentase 18,67\%. Kondisi tersebut terjadi karena beban biaya variabel pada setiap produksi akan selalu berbeda-beda yang disesuaikan dengan kebutuhan dan hambatan pada proses produksi.

Pada penelitian ini produk yang dihasilkan adalah gabah kering panen. Pada saat aktivitas berakhir maka biaya operasional dapat diperhitungkan. Biaya operasional budidaya tanaman padi di Kabupaten Karawang sebesar Rp. 24.001.903. Apabila biaya operasional budidaya diperhitungkan per kilogram maka perolehan biaya oprasional sebesar Rp. 3.531 per kilogram. Penjualan gabah di pasar diperoleh harga sebesar Rp.4.347 yang dikalikan dengan produktivitas maka petani memperoleh penerimaan sebesar Rp.27.888.604. sehingga diperoleh pendapatan petani per musim sebesar Rp.4.016.332 dan pendapatan per hari petani sebesar Rp.21.947.

\section{Analisis Perbedaan Biaya Operasional Budidaya Padi dengan Harga Pembelian Pemerintah (HPP)}

Biaya operasional budidaya per kilogram sebesar Rp.3.531 lebih rendah dari harga pembelian pemerintah yang sebesar Rp.3.700 sesuai INPRES 5/2015 tanggal 17 Maret 2015 namun penjualan pasar memiliki harga lebih tinggi dari harga pembelian pemerintah yaitu sebesar $\mathrm{Rp}$. 4.347. harga tersebut mengakibatkan petani lebih memilih menjual gabah kering panen ke pasar melalui tengkulak atau penggiling langsung.

Biaya operasional budidaya tanaman padi perkilogram sebesar Rp. 3.531 merupakan beban biaya keseluruhan selama aktivitas produksi tanaman padi, sedangkan pemerintah membeli gabah di petani yang ditetapkan dalam INPRES 5/2015 tanggal 17 Maret 2015 dengan harga gabah kering panen maksimum diberikan harga RP.3.700. Harga pembelian pemerintah dengan harga tersebut tidak seluruh petani dapat menutupi biaya budidaya tanaman padi.

Hasil pengolahan data didapatkan harga biaya budidaya tanaman padi per kilogram diatas harga pembelian pemerintah berjumlah 35 jiwa dengan persentase $38,60 \%$ dari keseluruhan jumlah responden. Artinya 35 jiwa apabila dijual kepada pemerintah masih memperoleh keuntungan. Sedangkan 22 jiwa dari responden petani mendapatkan harga biaya budidaya tanaman padi per kilogram diatas harga pembelian pemerintah sehingga apabila 22 petani menjual gabah kering panen kepada pemerintah maka petani mengalami kerugian. Perbandingan biaya operasional budidaya tanaman padi per kilogram dengan harga pembelian pemerintah diuji dengan One Sample T-Test melalui aplikasi SPPS dapat dilihat pada Tabel 4. 
Tabel 4. Analisis One Sample t-Test Biaya Budidaya Tanaman Padi dan Harga Gabah Non Pemerintah dengan Harga Pembelian Pemerintah Komoditas Gabah

\begin{tabular}{lcccc}
\hline \hline \multicolumn{1}{c}{ Pembanding } & Nilai Test & t Hitung & t Tabel & Signifikansi \\
\hline Biaya budidaya tanaman padi & 3.700 & 2,053 & 1,67203 & 0,045 \\
Harga non pemerintah & 3.700 & 27,871 & 1,67203 & 0,000 \\
\hline
\end{tabular}

Sumber: Data Primer Terolah SPSS, 2017.

Petani di Kabupaten Karawang lebih banyak yang menjual gabahnya tidak ke lembaga pemerintah atau bulog akan tetapi petani menjualnya ke pasar yang didistribusikan ke tengkulak atau penggiling langsung melihat harga yang ditawarkan tengkulak dan petani lebih besar dibandingkan dengan harga pembelian pemerintah. Perbedaan tersebut diuji dengan One Sample T-Test melalui aplikasi SPPS pada Tabel 4.

Berdasarkan hasil analisis One-Sample t-Test pada Tabel 4 diperoleh t hitung $>\mathrm{t}$ tabel dan signifikansi kurang dari 0,05 maka terdapat perbedaan harga gabah dari beban biaya budidaya tanaman padi dan harga pembelian gabah non pemerintah dengan harga pembelian pemerintah komoditas gabah terhadap keuntungan petani.

\section{Analisis Pola dan Margin Distribusi Pemasaran Gabah}

Pola distribusi pada penelitian ini yaitu menyalurkan barang dengan komoditas gabah sehingga gabah dapat diolah menjadi beras. Pola distribusi pemasaran gabah di Kabupaten Karawang dapat dilihat pada Tabel 5.

Tabel 5. Pola Distribusi Pemasaran Gabah di Kabupaten Karawang

\begin{tabular}{|c|c|c|c|}
\hline \multirow[b]{2}{*}{ Pola } & \multicolumn{3}{|c|}{ Jumlah } \\
\hline & Klasifikasi & Pola & Persentase \\
\hline & & -(Orang)- & $---(\%)---$ \\
\hline I & Pola rantai pendek Petani - Penggiling langsung & 19 & 33 \\
\hline II & Pola rantai panjang Petani - Tengkulak - Penggiling & 38 & 67 \\
\hline Tot & & 57 & 100 \\
\hline
\end{tabular}

Sumber : Data Primer Terolah, 2017.

Berdasarkan Tabel 5, pola satu merupakan pola rantai pemasaran melalui alur distribusi dari petani yang menjual gabah ke penggiling langsung yang kemudian dijadikan bahan baku penggillingan oleh penggiling. Sedangkan pola dua merupakan pola rantai pemasaran melalui alur distribusi dari petani yang menjual gabahnya kepada tengkulak kemudian tengkulak disalurkan kembali ke penggiling untuk diolah menjadi beras dan menjadi bahan baku dalam penggilingan.

\section{Margin Distribusi Pemasaran}

Margin distribusi pemasaran merupakan selisih harga yang terjadi dalam penyaluran barang dan jasa. Pada penelitian ini margin distribusi pemasaran dan rata-rata yang mendapat margin dari pola I dan II dapat dilihat pada Tabel 6. 
Berdasarkan Tabel 6 menunjukkan bahwa pola I tidak terjadi transaksi pemasaran disebabkan penyaluran gabah dilakukan secara langsung atau tidak adanya perantara antara petani dengan penggiling. Hal ini menunjukkan bahwa harga jual GKP ditingkat petani dan harga beli GKP ditingkat penggiling tidak adanya selisih harga sehingga margin pada pola I sama dengan 0. Berbeda dengan pola II, distribusi pemasaran gabah pada pola II terlihat adanya penyalur yaitu tengkulak. Persentase pembelian gabah ditingkat penggiling sebesar $100 \%$ dan penerimaan gabah di tingkat petani sebesar $94,28 \%$. Hal ini terjadi karena 5,72\% margin pemasaran diperoleh oleh tengkulak.

Tabel 6. Rata-Rata Margin Pemasaran Gabah di Kabupaten Karawang

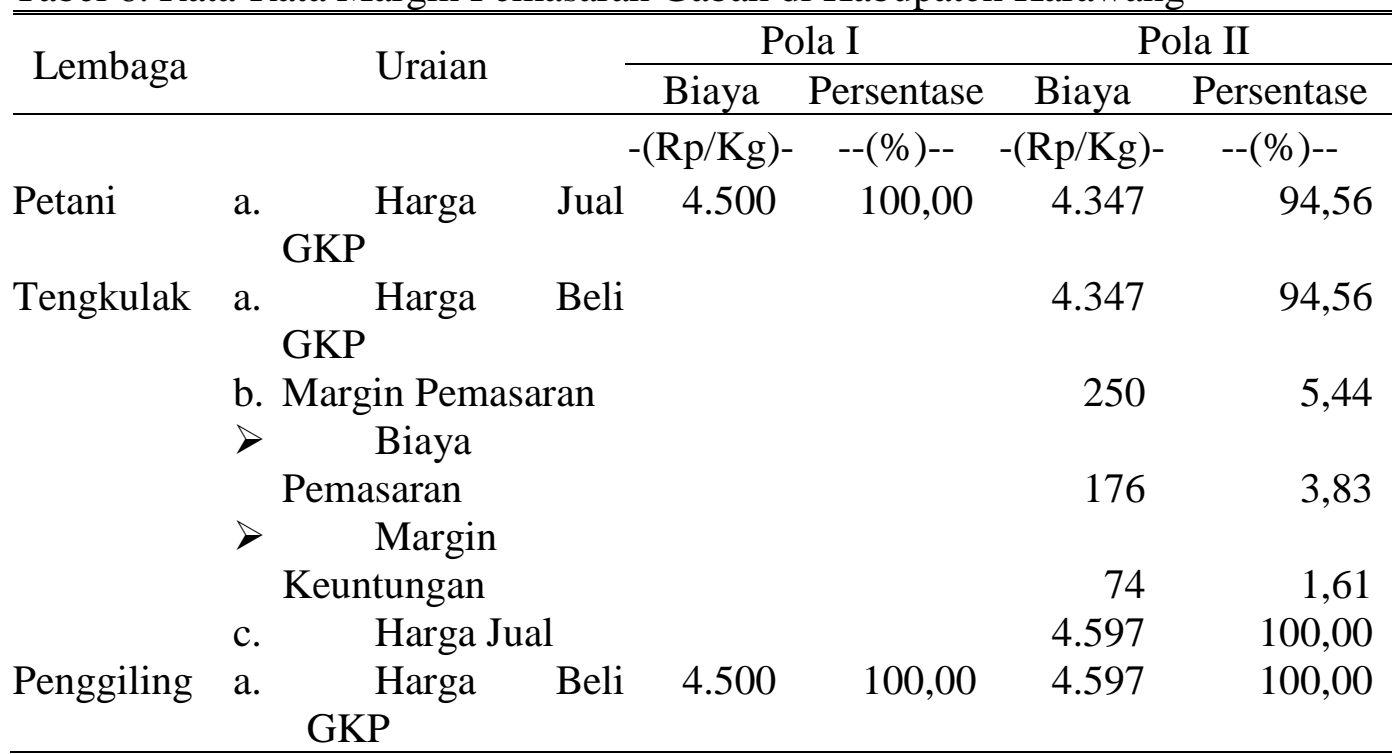

Sumber : Data Primer Terolah, 2017.

Perbandingan nilai margin antara pola I dengan pola II dikatakan lebih efisien pada pola I karena dilihat dari nilai farmer share sebesar $100 \%$ artinya nilai akhir dibagi nilai awal sama dengan 1 . Nilai efisien sama dengan satu. Petani akan lebih menguntungkan apabila melakukan pemotongan rantai dan melakukan distribusi pemasaran dengan pola I. Perbandingan antara pola I dengan pola II dilakukan dengan pengujian secara statistik dengan menggunakan analisis One Sample $t-$ Test yang dapat dilihat pada Tabel 7.

Tabel 7. Analisis One Sample $t$ - Test Margin Pemasaran.

\begin{tabular}{rcccc}
\hline \hline Pembanding & Nilai Test & t Hitung & t Tabel & Signifikansi \\
\hline Margin Pola Panjang & 0 & 120,380 & 2,0219 & 0,000 \\
\hline
\end{tabular}

Sumber : Data Primer Terolah, 2017.

Berdasarkan hasil analisis One-Sample t-Test diperoleh t hitung $>\mathrm{t}$ tabel dan signifikansi kurang dari 0,05 maka terdapat perbedaan margin pola pendek dengan margin pola panjang. Nilai margin uraian diatas menunjukkan bahwa 
dengan memotong saluran pemasaran akan meningkatkan pendapatan dan kesejahteraan petani yang dibuktikan dengan pola rantai pendek memiliki nilai 0 .

\section{KESIMPULAN DAN SARAN}

Berdasarkan analisis dan hasil penelitian dapat disimpulkan bahwa :

1. Terdapat perbedaan secara signifikan yang nyata antara harga gabah dari biaya budidaya padi dengan harga gabah pembelian pemerintah dan non pemerintah.

2. Terdapat dua pola pemasaran gabah yaitu pola panjang terdiri dari petani tengkulak - penggiling dengan persentase $67 \%$, dan pola pendek terdiri dari petani - penggiling dengan persentase $33 \%$.

3. Nilai margin untuk pola panjang sebesar Rp. 250 per kilogram sedangkan pola pendek Rp. 0 per kilogram. Terdapat perbedaan margin pola panjang dengan margin pola pendek secara signifikan.

\section{Saran}

Saran pada penelitian ini yaitu:

1. Mengingat harga pembelian pemerintah yang berada diatas biaya operasional budidaya tanaman padi per kilogram maka diperlukan peningkatan nilai. Hal ini agar petani lebih sejahtera disamping harga tengkulak yang lebih besar dibandingkan dengan harga pembelian pemerintah.

2. Disarankan Petani menggunakan pola I karena pada pola I yaitu petani yang menjual ke penggiling langsung tidak memiliki nilai margin atau nilai margin sama dengan Rp. 0. Hal ini dapat dilakukan dengan cara jalinan kerjasama atau bermitra antara petani dengan penggiling.

\section{DAFTAR PUSTAKA}

Badan Ketahanan Pangan Pertanian. 2015. Instruksi Presiden Republik Indonesia Nomor 5 Tahun 2015. Presiden Republik Indonesia, Jakarta.

Badan Pusat Statistik. 2015. Nilai Produksi dan Biaya Produksi per Musim Tanam per Hektar Budidaya Tanaman Padi Sawah, Padi Ladang, Jagung, dan Kedelai, 2014. BPS Pusat, Jakarta. Tidak diterbitkan. www.bps.go.id. Diakses pada tanggal 1 Maret 2017.

Badan Pusat Statistik. 2016. Rata-Rata Harga Gabah Menurut Kualitas, Komponen Mutu dan HPP di Tingkat Penggilingan di Indonesia, 20082016. BPS Pusat, Jakarta.

Badan Pusat Statistik. 2016. Rata-Rata Harga Gabah Menurut Kualitas, Komponen Mutu dan HPP di Tingkat Petani di Indonesia, 2008-2016. BPS Pusat, Jakarta Fanini, Z. 2012. Manajemen Pemasaran. UMM Press, Malang.

Ekowati, T., D. Sumardjono dan H. Setiyawan. 2014. Usahatani. Agribisnis, Fakultas Peternakan dan Pertanian Universitas Diponegoro, Semarang. 
Fauzy, A. 2011. Statistik Industri cetakan ke-4. Penerbit Erlangga, Jakarta.

Kadarrisman. 2016. Karawang Surplus Beras 500 Ribu Ton Per Tahun. Pikiran Rakyat. 2 Desember 2016 Pukul 15.04 WIB. 